\title{
Nocturnal polyuria and saluresis in renal allograft recipients
}

\author{
M K CHAN, Z VARGHESE, O N FERNANDO, J F MOORHEAD
}

\section{Summary and conclusions}

The evolution of nocturnal polyuria and saluresis in renal allograft recipients was studied by comparing the day to night $(D: N)$ ratios of urine volume and sodium excretion in 15 patients who had undergone transplantation less than one year previously (recent-transplant group) with those in 11 patients who had undergone transplantation at least one year previously. Eleven patients with chronic renal failure and 12 normal subjects served as controls. Patients in the recent-transplant group had significantly lower $D: N$ ratios of urine volume and sodium excretion than the patients who had undergone transplantation at least a year before, while the ratios in this last group did not differ significantly from those in the normal subjects. Nocturnal polyuria and saluresis gradually subsided in five patients studied for three months.

Chronic renal failure and uraemic autonomic neuropathy were unlikely causes of the nocturia. The patients in the recent-transplant group had significantly lower $D: N$ ratios of urine volume than the controls with chronic renal failure, and the mean Valsalva ratio in eight of them was not significantly different from that in the normal subjects. An undue sensitivity of renal allografts to postural influences was proposed.

\section{Introduction}

Complaints of nocturnal polyuria by renal allograft recipients prompted us to conduct a study investigating the cause of this phenomenon.

\section{Subjects, methods, and results}

We studied 15 patients who had undergone transplantation fairly recently - that is, from the time their plasma creatinine concentration stabilised to about 10 months after operation-and 11 patients at least one year after transplantation. Eleven patients with chronic renal

Department of Nephrology and Transplantation, Royal Free Hospital, London NW3 2QG

M K CHAN, MB, MRCP, registrar (now research fellow)

Z VARGHESE, MSC, PHD, principal biochemist

O N FERNANDO, FRCS, FRCSED, consultant surgeon

J F MOORHEAD, MB, FRCP, director failure and 12 normal subjects served as control groups. No patients were taking diuretics or beta-blockers. Urine was collected 12-hourly, from 0800 to 2000 (day collection) and from 2000 to 0800 (night collection). Aliquots from each sample were taken for measurement of creatinine, sodium, and potassium concentrations. Blood was taken for estimation of the plasma creatinine concentration, and the day and night creatinine clearances were estimated from the same plasma sample. Patients in the recent-transplant group were studied for three months, the frequency of sampling varying from thrice weekly to once monthly. The patients entered the study at different times after transplantation. The remaining patients and the controls were studied for at least three consecutive days.

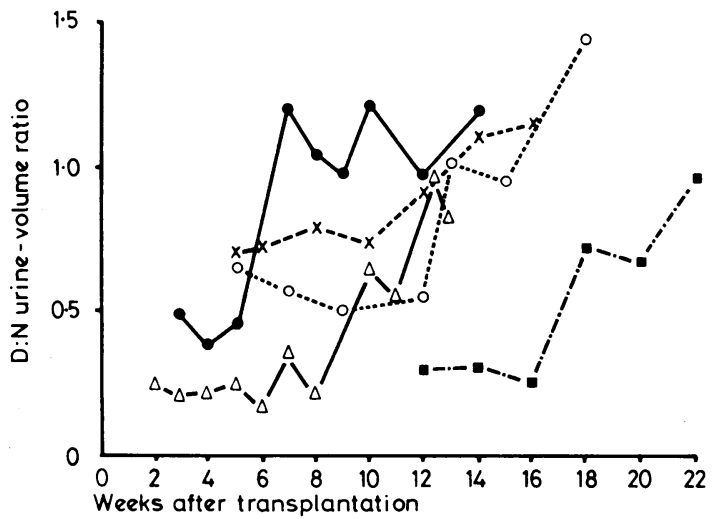

Day:night $(D: N)$ urine-volume ratios in five patients after transplantation.

\section{Results}

Results were expressed as mean ratios of the day to night $(D: N)$ values (table). The figure shows the $\mathrm{D}: \mathrm{N}$ ratios of urine volume in five patients studied at regular one- to two-weekly intervals for over 10 weeks. The Valsalva ratio $^{1}$ was determined to assess autonomic function in eight patients in the recent-transplant group and in $\mathbf{4 2}$ healthy volunteers. The difference between the two groups was not significant (mean \pm SE of mean ratio $1.62 \pm 0.11$ (patients) and $1.8 \pm$ 0.33 (volunteers); Student's $t$ test).

\section{Discussion}

Our study confirmed that nocturnal polyuria was common up to 10 months after transplantation and that it disappeared in patients studied at least a year after operation (see figure). We did not study the diurnal rhythm of water and salt excretion in

Mean $( \pm S E$ of mean) day to night $(D: N)$ ratios of urine volume, sodium and potassium excretions, and creatinine clearance and 24-hour creatinine clearance in patients studied up to 10 months after transplantation (recent-transplant group) and those studied at least a year after transplantation, patients with chronic renal failure, and normal controls

\begin{tabular}{|c|c|c|c|c|c|c|c|c|c|c|}
\hline & & & & $\begin{array}{c}\text { Chronic } \\
\text { renal } \\
\text { failure } \\
(5 \mathrm{M}, 6 \mathrm{~F}) \\
\end{array}$ & $\begin{array}{c}\text { Significance } \\
\text { of } \\
\text { difference }\end{array}$ & $\begin{array}{c}\text { Recent- } \\
\text { transplant } \\
\text { group } \\
(7 \mathrm{M}, 8 \mathrm{~F}) \\
\end{array}$ & $\begin{array}{c}\text { Significance } \\
\text { of } \\
\text { difference }\end{array}$ & $\begin{array}{c}\text { Group studied } \\
\text { at least } 1 \text { year } \\
\text { after } \\
\text { transplantation } \\
(5 \mathrm{M}, 6 \mathrm{~F})\end{array}$ & $\begin{array}{c}\text { Significance } \\
\text { of } \\
\text { difference }\end{array}$ & $\begin{array}{c}\text { Normal } \\
\text { subjects } \\
(8 \mathrm{M}, 4 \mathrm{~F}) \\
\end{array}$ \\
\hline $\begin{array}{l}\mathrm{D}: \mathrm{N} \text { ratio of: } \\
\text { Urine volume } \\
\text { Urine sodium } \quad \ldots \\
\text { Urine potassium ... } \\
\text { Creatinine clearance }\end{array}$ & $\begin{array}{l}\cdots \\
\cdots \\
\cdots\end{array}$ & $\begin{array}{l}\cdots \\
\cdots \\
\cdots\end{array}$ & $\begin{array}{l}\cdots \\
\cdots \\
\cdots\end{array}$ & $\begin{array}{l}1 \cdot 11 \pm 0 \cdot 13 \\
1 \cdot 02 \pm 0 \cdot 18 \\
1 \cdot 41 \pm 0 \cdot 23 \\
1 \cdot 02 \pm 0 \cdot 10\end{array}$ & $\begin{array}{l}p \leqslant 0.05 \\
\text { NS } \\
p \leqslant 0.05 \\
\text { NS }\end{array}$ & $\begin{array}{l}0 \cdot 76 \pm 0.06 \\
0 \cdot 79 \pm 0.07 \\
0 \cdot 89 \pm 0.07 \\
0.97 \pm 0.03\end{array}$ & $\begin{array}{l}p \leqslant 0.01 \\
p \leqslant 0.01 \\
p \leqslant 0.01 \\
p \leqslant 0.05\end{array}$ & $\begin{array}{l}1 \cdot 38 \pm 0 \cdot 19 \\
1 \cdot 42 \pm 0 \cdot 20 \\
1 \cdot 80 \pm 0 \cdot 28 \\
1 \cdot 27 \pm 0 \cdot 11\end{array}$ & $\begin{array}{l}\text { NS } \\
\text { NS } \\
\text { NS } \\
\text { NS }\end{array}$ & $\begin{array}{l}1 \cdot 59 \pm 0.39 \\
1 \cdot 48 \pm 0 \cdot 40 \\
2 \cdot 18 \pm 0.57 \\
1 \cdot 16 \pm 0.16\end{array}$ \\
\hline \multicolumn{3}{|c|}{ 24-hour creatinine clearance $(\mathrm{ml} / \mathrm{min})$} & .. & $54 \cdot 2 \pm 7 \cdot 3$ & NS & $57 \cdot 7 \pm 6 \cdot 4$ & NS & $73 \cdot 6 \pm 8 \cdot 9$ & $\mathrm{p} \leqslant 0.01$ & $121 \cdot 1 \pm 6 \cdot 3$ \\
\hline
\end{tabular}

Significance of difference determined by Wilcoxon's rank sum test. NS $=$ Not significant. 
our patients. Our results, however, indicate that conflicting reports ${ }^{2} 3$ about the diurnal rhythm of water and salt excretion in renal allograft recipients are explicable by the fact that the patients were studied at different times after transplantation. Although nocturia is common in renal failure, our results clearly show that renal failure alone cannot account for nocturia in patients who have recently undergone transplantation since these patients had significantly lower $D: N$ ratios of urine volume than those with renal failure with comparable creatinine clearances $(p \leqslant 0.05)$; the patient with the severest nocturia (case 1) had normal renal function; and the patients studied at least a year after transplantation had normal $\mathrm{D}: \mathrm{N}$ ratios of urine volume, although their mean creatinine clearance was significantly lower than that in the normal subjects $(p \leqslant 0.01)$. Other possible causes of the nocturia are discussed below.

Autonomic neuropathy-Autonomic dysfunction ${ }^{4}$ produces nocturnal polyuria and saluresis. It is tempting to postulate that autonomic dysfunction, which is common in patients receiving dialysis, ${ }^{5}$ might account for the nocturia in the first few months after transplantation and that as the allograft continues to function the autonomic dysfunction is corrected, thereby normalising water and salt excretion. None of our patients, however, had postural hypotension or other clinical signs of autonomic neuropathy, and the cardiovascular reflex in eight patients in the recent-transplant group as assessed by the Valsalva ratio was not significantly different from that in $\mathbf{4 2}$ healthy volunteers. While a normal Valsalva ratio probably excludes gross autonomic dysfunction, an abnormal ratio does not establish the presence of autonomic neuropathy, since the ratio is reduced in cardiac insufficiency. ${ }^{1}$

Allograft positions-Although the allograft's position may have some unknown haemodynamic influence on its function, it cannot be responsible for the early nocturnal polyuria since the abnormality corrects itself with time while the kidney remains in the same position.

Influence of drugs-Since all our patients who had received transplants took prednisolone at 2000 the mineralocorticoid activity of the drug would be expected to reduce nocturnal sodium excretion, whereas the opposite was observed. The nocturnal kaliuresis in patients in the recent-transplant group was probably caused by the combined effects of urine volume and steroids given at night.

Postural influence-The reported normal diurnal rhythm of water excretion in renal allograft recipients when the influence of posture has been eliminated ${ }^{6}$ suggests that the denervated kidney is unduly sensitive to postural changes. This is supported by our observation that when the patient in case 1 remained recumbent for 24 hours the nocturia was almost completely abolished (D:N urine-volume ratio changed from 0.35 to 0.90 ) while the dose of immunosuppressive drugs remained unaltered. It is not known why this supersensitivity to postural changes disappeared at least a year after transplantation, although gradual adaptation of the denervated vasculature is possible. Whether or not re-enervation of the graft ${ }^{7}$ plays a part remains speculative.

Our study has shown that renal allograft recipients often have nocturia, which abates spontaneously, usually within a year after operation. It is not due to renal insufficiency, autonomic neuropathy, or immunosuppressive drugs but is related to postural influences. Patients who have received transplants and who complain of nocturia should be reassured that it will eventually disappear.

\section{References}

1 Levin AB. A simple test of cardiac function based upon the heart rate changes induced by the Valsalva maneuver. Am 7 Cardiol 1966;18:90-9.

2 Berlyne GM, Mallick NP, Seedat YK, Edwards EC, Harris R, Orr WMcN. Abnormal urinary rhythm after renal transplantation in man. Lancet 1968;ii:435-6.

3 Dosseter JB, Morgan RO, Beck JC. Observations on the function of a transplanted kidney. Can $\mathcal{F}$ Biochem Physiol 1963;41:1409-22.

4 Wilcox CS, Aminoff MJ, Slater JDH. Sodium homeostasis in patients with autonomic failure. Clin Sci Molec Med 1977;53:321-8.

5 Ewing DJ, Winney R. Autonomic function in patients with chronic renal failure on intermittent haemodialysis. Nephron $1975 ; 15: 424-9$.

${ }^{6}$ Koene R, van Liebergen F, Wijdeveld P. Normal diurnal rhythm in the excretion of water and electrolytes after renal transplantation. Clin Nephrol 1973;1:266-70.

7 Gazdar AF, Dammin GJ. Neural degeneration and regeneration in human renal transplants. $N$ Engl f Med $1970 ; 283: 222-4$.

(Accepted 12 October 1979)

\section{Cimetidine for pruritus in Hodgkin's disease}

Cimetidine is a potent histamine $\mathrm{H}_{2}$-receptor antagonist that has proved useful in digestive disorders with gastric-acid hypersecretion. ${ }^{1}$ It has been used for pruritus related to cholestasis, ${ }^{2}$ chronic renal failure, ${ }^{3}$ and myeloproliferative disorders. ${ }^{4}$ These reports have prompted us to try the drug in four cases of pruritus due to Hodgkin's disease.

\section{Case reports}

(1) A 24-year-old woman was admitted because of low back pain, weight loss, night sweats, and intense generalised pruritus. Biopsy of a left supraclavicular lymph node showed Hodgkin's disease, nodular sclerosis type. Staging laparotomy was not performed because of lymphographic abnormalities of the retroperitoneal nodes. Cimetidine by mouth was started at a dose of $1 \mathrm{~g}$ daily ( $200 \mathrm{mg}$ at mealtimes three times a day, and $400 \mathrm{mg}$ at bedtime). The pruritus completely disappeared within 24 hours. The itching returned within 12 hours when cimetidine was stopped and disappeared when it was restarted. Cimetidine was withdrawn when chemotherapy (MOPP regimen) was begun. Pruritus did not recur.

(2) A 19-year-old woman was referred to us because of enlarged cervical and mediastinal lymph nodes and a three-month history of lassitude, sweats, and generalised pruritus. Biopsy of a cervical node showed lymphocytedepleted Hodgkin's disease. She was given cimetidine $1 \mathrm{~g}$ daily by mouth
(200 mg at mealtimes and $400 \mathrm{mg}$ at bedtime). This dramatically reduced itching and sweats within one day. Pruritus and sweats returned within 12 hours when cimetidine was withdrawn.

(3) A 29-year-old woman with a six-month history of severe pruritus and night sweats was admitted with cervical and mediastinal lymphadenopathy. Biopsy of a cervical node showed nodular sclerosing Hodgkin's disease. We tried dexchlorpheniramine for the itching effect. Cimetidine by mouth $1 \mathrm{~g}$ daily ( $200 \mathrm{mg}$ at mealtimes and $400 \mathrm{mg}$ at bedtime) was given. Relief from the pruritus and sweats was progressive and complete within four days. Cimetidine was stopped, without any recurrence of itching, when the patient began a MOPP regimen.

(4) A 22-year-old woman was admitted for fever, sweats, pruritus, and cervical, axillary, and inguinal lymphadenopathy. Biopsy of an inguinal lymph node showed nodular sclerosing Hodgkin's disease. Four cycles of MOPP were given. Pruritus and fever reappeared soon after the fourth course of MOPP. Cimetidine $1 \mathrm{~g}$ daily by mouth $(200 \mathrm{mg}$ at mealtimes and $400 \mathrm{mg}$ at bedtime) was started. Within four days her pruritus was completely relieved. Cimetidine was discontinued without immediate recurrence of itching. It was successfully resumed 10 days later for a recurrence of itching.

\section{Comment}

Severe generalised pruritus is not uncommon in Hodgkin's disease. Its pathogenesis is poorly understood, and treatment with systemic or topical medications is often disappointing. Itching was relieved in all our patients by cimetidine alone-within a day in two cases and after a few days in the other two. When treatment was stopped itching 